\title{
Matrilin-3 gene polymorphism in primary knee osteoarthritis: Evidence based systematic review
}

\author{
Arun Kumar Sharma ${ }^{1}$, Rajbeer Singh², Devendra Singh ${ }^{3}$, Anurag Shukla ${ }^{4}$, \\ Ramesh C Meena ${ }^{5}$, Divyanshu Goyal ${ }^{6}$, Priyanka Sharma7, Uday Raman ${ }^{8}$ \\ ${ }^{1}$ Assistant Professor, ${ }^{5}$ Professor, ${ }^{6}$ Senior Resident, ${ }^{8}$ Junior Resident, Department of Orthopaedics, SMS Medical \\ College, Jaipur, ${ }^{2}$ Medical Officer, Department of Orthopedics, Govt Medical College, Bharatpur, Rajasthan, India, \\ ${ }^{3}$ Assistant Professor, Department of Orthopedics, SN Medical College Jodhpur, India, ${ }^{4}$ Assistant Professor, Department \\ of Orthopedics, ELMC Lucknow (UP) India, ${ }^{7}$ Physiotherapist, Department of PMR, SMS Medical College, Jaipur, India
}

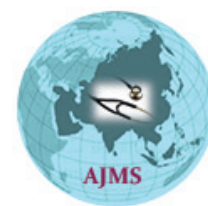

\section{A B S T R A C T}

There have been few studies in English literature identifying the potential association and clinical significance of MATN-3 rs8176070 (SNP6) polymorphism in patients with primary knee Osteoarthritis Knee. The objective of this review was to evaluate the association of matrilin gene-3 and primary osteoarthritis of knee through systematic review of these studies. We did an extensive literature using relevant keywords and eligible studies were included for systematic review. Two studies showed significant association, in which patients with the $B \backslash b$ genotype had worse clinical and radiological findings than those with $B \backslash B$ and $b \backslash b$ genotype. The third study in Indian population did not find any correlation. On the basis of this systematic review we can safely suggest that there is dearth of such studies in literature therefore more of such studies with wider and larger study population shall be undertaken to find Correlation of genetic in this multifactorial disorder and possible cure.

Key words: Matrilin gene -3; Osteoarthritis knee; Gene polymorphism; Kellgren-Lawrence Grade; Restriction fragment length polymorphism

\section{Access this article online}

Website:

http://nepjol.info/index.php/AJMS DOI: 10.3126/ajms.v11i4.29042

E-ISSN: 2091-0576

P-ISSN: 2467-9100

Copyright (c) 2020 Asian Journal of Medical Sciences

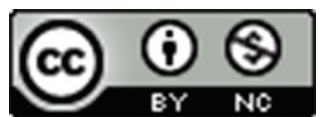

This work is licensed under a Creative Commons Attribution-NonCommercial 4.0 International License.

\section{INTRODUCTION}

Osteoarthritis is probably the most common disease of joints in adults throughout the world. ${ }^{1}$ With the increasing life expectancy and change in lifestyle, the prevalence of osteoarthritis is increasing substantially with a hundred percent increase in prevalence of new osteoarthritis since the mid- $20^{\text {th }}$ century. ${ }^{2}$ Knee OA accounts for more than $80 \%$ of the disease's total burden and affects at least $19 \%$ of American adults age equal to or more than 45 years. ${ }^{3}$ Systematic data regarding the prevalence is available from Western countries like United States where it has been estimated to effect 20 billion people with prevalence greater than $60 \%$ in subjects older than 70 years. ${ }^{4}$ Community survey data in rural and urban areas of India shows the prevalence to be in the range of 17 to 60.6 percent.,

Osteoarthritis is degenerative disorder that is progressive in nature. It is characterized by functional impairment of the cartilage, subchondral bone changes and osteophyte formation in the absence of autoimmune or antiinflammatory mechanism. ${ }^{7}$

It is assumed that the genetic changes affecting the synthesis of cartilage might have a role to play in the development of primary osteoarthritis. The risk of developing osteoarthritis depends upon interplay of both systematic and local factors. 
Local factors are most commonly biochemical in nature and adversely affect the forces applied to the joint. ${ }^{8}$ Osteoarthritis is a multifactorial disease and many factors have been implicated in etiology like obesity and metabolic disease, age, sex, ethnicity and race, genetics, sex, nutrition, smoking, bone density and muscle function. Several systematic factors have also been associated; by making the joint more vulnerable to injury, by direct/indirect damage or by impairing process of healing. ${ }^{9}$ Twin and family studies have estimated the heritable compound of $\mathrm{OA}$ to be between 50 and $65 \%$ with larger genetic influences for hand and hip osteoarthritis then for knee osteoarthritis. Use of restriction fragment length polymorphisms within and around the type II collagen gene on chromosome 12 showed a linkage between this cartilage-specific gene and primary OA of knee. $^{10,11}$ In a genome-wide association study, Kerkhof et al identified a novel locus involved in susceptibility for prevalence and progression of OA, SNP rs3815148 close to the GPR22 gene, in the largest association analysis in the genetics of Osteoarthritis till date. They included 14,938 osteoarthritis cases and approximately 39,000 controls. They reported that the $\mathrm{C}$ allele of rs3815 148 on chromosomes $7 \mathrm{q} 22$ was associated with 1.14-fold increased prevalence of knee and hand $\mathrm{OA}$ and also with a 30\% increased risk of knee OA progression. ${ }^{12}$ Several studies also found that there is an inverse relationship between generalized joint hyper mobility, a lone benign trait, with osteoarthritis of hand and knee and serum cartilage oligometric Matrix protein levels. ${ }^{13,14}$

Keeping in view the significance of genetic factors in development of primary osteoarthritis, a number of genome wide association studies (GWAS) have attempted to seek the relationship between genetic changes and osteoarthritis. It has been demonstrated in these studies that single nucleotide polymorphisms (SNPs) in various genes are related to an increased risk of knee osteoarthritis including collagen genes (COL1A1,COL2A1,COL9A1,COL11A2) 1 interleukin 1 receptor(IL1R), transforming growth factor ( TGFB 1) cartilage Matrix protein 1(CMP1), tissue in a beta of metalloproteinase 3 insulin like growth factor 1 bone morphogenetic protein(BMP), vitamin D receptor(VDR) aggrecan 1 (AGF1), secreted frizzled related protein3 (FRZB), growth differentiating factor 5 (GDF5) and cyclooxygenase 2(COX-2). Over the years those genetic studies have proved that degenerative osteoarthritis has a strong genetic component. Still the genetic role is complex, as it does not follow the typical mendelian inheritance. Interplay and role of multiple gene i.e. Polygenic inheritance have been supported by various studies vis a vis a single gene. ${ }^{15,16}$

Cartilaginous tissues contain a considerable amount of MATN-3 protein, which plays a vital role in the configuration of the collagen (collagen IX)-dependent network, linking cells together, and the collagenindependent peri-cellular network. ${ }^{17}$ Klat Mutations in MATN-3 have been found to be associated with etiopathogenesis of many disorders, namely dysplastic disorders including hereditary multiple epiphyseal dysplasia and spondyloepimetaphyseal dysplasia, and make population susceptible to develop OA. ${ }^{18,19}$

It has been shown that single nucleotide polymorphism of MATN-3 gene is associated with primary osteoarthritis in patients with different ethnicities. Although Indian population has high prevalence of OA knee still genetic studies for $\mathrm{OA}$ in Indian perspective are scarce and likewise there had been no scientific and critical review of published studies exploring association of matrilin gene 3 in osteoarthritis knee. Therefore, the present critical review was carried out to appraise the association between multilink 3 gene polymorphism and primary knee osteoarthritis by critically reviewing the published literature.

\section{MATERIAL AND METHODS}

This systematic review was reported according to the preferred reporting items for systematic reviews and metaanalyses (PRISMA) guidelines. All analyses were based on previous published studies; thus, no ethical approval and patient consent are required.

We searched PubMed / Medline, Scopus, EBSCO, HMIC, Embase, Hinari and Cochrane databases using keywords "matrilin gene 3 in osteoarthritis knee", "genetics in osteoarthritis knee" and "Mat-gene3". Key words for the search were those which would retrieve articles evaluating the association of matrilin gene 3 associations in osteoarthritis knee. Additionally, we searched Google and Google scholar data base. Our search retrieved various articles, exploring association of matrilin-3 gene with osteoarthritis of knee published between January 01, 1980, and April 2020, in English language. The meta-analysis, review articles, case reports and letter to editors were excluded from this review. The matrilin gene was broadest term which yielded 370 results, while matrilin gene in osteoarthritis produced 75 results. The narrower term in hierarchy, matrilin gene 3 in osteoarthritis produced only 7 results proving our notion and primary vision right that genetic studies have yet to make a quantitative exploration in osteoarthritis knee. All 7 articles were thoroughly read and only those articles that were associated with genetic analysis of matrilin 3 gene with Osteoarthritis knee were included for review. The references of these articles were also manually searched for any missing article. One more article in Google search was found as that journal was not 
PubMed indexed but on brighter note it was an study done on Indian population..$^{20}$ This third article is most recent, had Indian cohort and gave our review an ethnically wider population base to review the association of matrilin 3 in osteoarthritis knee.

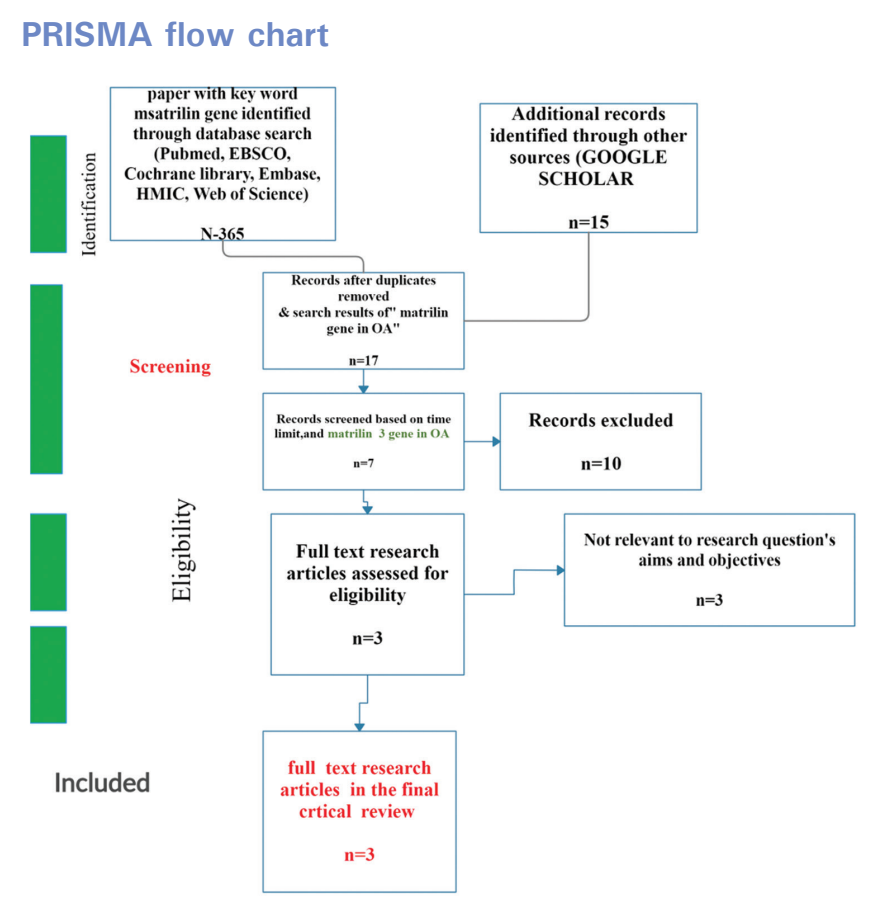

\section{RESULTS}

All 3 relevant studies matched in study type and level of evidence as all 3 were case control studies (level of evidence-3) conducted in 3 part of globe at different time frames Independent of each other.

\section{Study subjects}

First study in Chinese Han population recruited a total of 420 patients with OA (216 women and 204 men) and 312 healthy controls (156 women and 156 men). This study, unlike other 2 studies described infra, recruited patients with lumbar OA, hand OA and cervical OA too. Among all patients, 108 patients with knee $\mathrm{OA}$ were in the age ranged from 40 to 79 with a mean age of $60.22 \pm 6 .{ }^{21}$ Study Duration was 2005 to September 2009and site of study was Harbin Medical University, Heilongiiang, Harbin, China.

The Egyptian and Indian case-control study included 50 primary knee OA patients (Group I) fulfilling the American College of Rheumatology (ACR) classification criteria of knee $\mathrm{OA}^{22}$ who attended Benha University hospital and ELMC Lucknow hospital Uttar Pradesh, India respectively, together with 50 age and sex-matched apparently healthy controls (Group II) with no symptoms or signs on clinical examination or radiographic changes indicative of knee OA or other joint disease. ${ }^{20,23}$ Our interesting observation was that Indian study seems to draw its inspiration from Egyptian therefore patient cohort, methodology, criterion for inclusion / exclusion seem to mirror each other. Both studies excluded the patient having isolated patello-femoral $\mathrm{OA}$; secondary OA due to trauma or deformity; metabolic disorders such as diabetes mellitus, thyroid disorders, or Cushing syndrome; or renal failure or were undergoing dialysis; infectious disorders such as septic arthritis, viral arthritis, or fungal arthritis; inflammatory arthritis such as rheumatoid arthritis, systematic lupus erythematosus, and sero-negative arthritis; malignancy; bilateral knee replacements; or relatives included in the study.

Egyptian study duration was the period from February 2015 to May 2015 while Indian study took place between November 2017 to October 2019.Mean age of Indian study group was (59.6 \& 60 for case and control) while in Egyptian group it was ( $60.36 \& 58.48$ for case and control). Hence age group of patients was comparable in all 3 studies. The Kellgren-Lawrence grading was used to assess disease severity reflecting on radiographs in all 3 studies. Radiographic findings of $\mathrm{OA}$ were classified into mild (Kellgren-Lawrence grade 1 or 2) and severe (KellgrenLawrence grade 3 or 4$).{ }^{24}$ The functional or symptomatic statuses of $\mathrm{OA}$ patients were classified as functionally or symptomatically good (Lequesne's functional index $=10$ ) and poor (Lequesne's functional index $>10$ ). ${ }^{25}$

\section{Analysis of MAT-3 gene polymorphism}

Blood samples from patients and controls were collected by Vacutainer tubes and were transferred to EDTA tubes. DNA was extracted from the peripheral blood leucocytes by standard phenol/chloroform extraction techniques and precipitation with ethanol.

\section{MATN3 Genotyping}

Genotyping of MATN3 SNP6 was assayed with the polymerase chain reaction restriction fragment length polymorphism (PCR-RFLP) was employed for genotyping of candidate gene MATN3SPN6 The polymerase chain reaction (PCR) was conducted in a reaction volume of $25 \mu \mathrm{L}$ with $10 \mathrm{ng}$ genomic DNA, $10 \times$ PCR buffer, $100 \mu$ MdNTPs, 5 pmol of each primer, and 0.5 unit of Taq polymerase (Neurotics Inc., Seoul, Republic of Korea). "The PCR primers 5'-GGACAGGATCCCACAAAAAG-3' was used as forward primer and 5'-GAAAGAGGGGCTACAACAGG-3' was used as reverse primer."

Steps of amplification included 35 cycles consisting of 1 min of denaturation at $95^{\circ} \mathrm{C}$, one min of annealing at $61^{\circ} \mathrm{C}, 1 \mathrm{~min}$ of extension at $72^{\circ} \mathrm{C}$ with an initial denaturation step of $10 \mathrm{~min}$ at $95^{\circ} \mathrm{C}$, and a final extension of $10 \mathrm{~min}$ at $72^{\circ} \mathrm{C}$ in a thermo cycler (Techne, TC-312, UK). 
The resultant PCR showed single fragment at $501 \mathrm{bp} .10 \mu \mathrm{L}$ of 501-bp product were then digested with restriction enzyme (NEB-R0635S) at $37^{\circ} \mathrm{C}$ for $10 \mathrm{~h}$. Digestion products were visualized on a $3 \%$ agarose gel containing ethidium bromide. The RFLPs were coded as Bb, where the uppercase letter signifies the absence of the restriction site and the lowercase letter signifies the presence of the site. Wild-type genotype (CC) which coded as bb produced double band at 149 and $352 \mathrm{bp}$, heterozygote $(\mathrm{CN})$ which coded as Bb produced three bands at 501,149 and $352 \mathrm{bp}$, and homozygote polymorphic genotype $(\mathrm{NN})$ which coded as $\mathrm{BB}$ produced only one band at $501 \mathrm{bp}$.

\section{Analytical statistics}

All three studies employed same statistical methods hence were comparable. All statistical analyses were performed with SPSS version 15.0 software (SPSS Inc., Chicago, IL, USA).

In statistical comparison between different groups, the statistical significance was defined as $\mathrm{p} \leq 0.05(*)$, while a p-value of $>0.05$ was insignificant. A p-value of $<0.001$ was considered highly significant $(* *)$. In the studied groups, the representativeness of alleles and genotypes was estimated by the Hardy-Weinberg equilibrium (HWE) by comparing the observed and expected frequencies of genetic variants. Logistic regression analysis was applied to examine association between SNP variants and the risk of OA. The differences in genotype and allele distributions were analyzed by the chi-square $(\chi 2)$ test and represented by odds ratios (ORs) and 95\% confidence intervals (CIs). A p-value of $<0.05$ was considered statistically significant at a confidence interval (CI) of $95 \%$.

\section{Results}

Chinese study suggested that the investigated polymorphism in the MATN3 gene might play a role in osteoarthritis in the Han population. Further study with a larger population size remains to be conducted for a definitive affirmation of correlates of MATN3 gene polymorphism in osteoarthritis patients. Gu et al studied on $732 \mathrm{OA}$ cases with a mean age of $57.4 \pm 9.5$ years from china and revealed that the $\mathrm{B} \backslash \mathrm{B}$ genotype increased the risk of $\mathrm{OA}(\mathrm{OR}=1.724$, 95\% CI $=1.071-2.770 ; \mathrm{p}=0.025)$ especially knee $\mathrm{OA} .{ }^{21}$ Additionally, they stated $\mathrm{B}$ allele might have associated with increased knee $\mathrm{OA}(\mathrm{OR}=3.143,95 \% \mathrm{CI}=2.283-4.328$; $\mathrm{p}=0.000)$ compared with control subjects.

The Egyptian study revealed more severe knee OA patients with the $B \backslash b$ genotype, while patients with the $\mathrm{b} \backslash \mathrm{b}$ genotype showed less severe disability and radiological severity than those with the $\mathrm{B} \backslash \mathrm{b}$ genotype. ${ }^{23}$ Patients with the $B \backslash B$ genotype had the least disability, and their radiological findings were the mildest. This means that patients with the $\mathrm{B} \backslash \mathrm{b}$ genotype had worse clinical and radiological findings than other those with the $\mathrm{B} \backslash \mathrm{B}$ and $\mathrm{b} \backslash \mathrm{b}$ genotypes. In conclusion, the investigated polymorphism in the $M A T N-3$ gene may reflect the risk and severity of knee $\mathrm{OA}$ in the Egyptian population, particularly with the $\mathrm{B} \backslash \mathrm{b}$ genotype. They Postulated that prevalence of $\mathrm{B} \backslash \mathrm{b}$ genotype $(p=0.046)$ and $b$ allele $(p=0.042)$ was more evident in OA patients with a high risk of OA development. Patients with the $\mathrm{B} \backslash \mathrm{b}$ genotype had poorer clinical and radiological scores than those with $B \backslash B$ and $b \backslash b$ genotypes. This dilemma regarding outcome variation may be explained by ethnic differences related to geographic distribution.

Notably, genotype and allele frequency were not significantly associated with the severity of the disease in the Indian population. ${ }^{20}$ One of the reasons behind these observations could be the small sample size involved in the study. Another reason as per the researcher "may be already the existence of MATN3 gene mutation in the Indian population, which is vindicated by us unable to find any association of MATN3 with primary knee OA". In the Indian study, HWE was estimated for Indian genotypes for both cases and controls. According to HWE theorem, allele and genotype frequencies in a population will remain constant from generation to generation in the absence of other evolutionary influences include mutation genetic shift genetic drift, mate choice, assortative mating, natural or sexual selection etc.

\section{DISCUSSION}

Osteoarthritis is most common form of arthritis.13\% of female and $10 \%$ of male populations older than 60 years have symptoms of osteoarthritis of knee. ${ }^{1}$ The proportion of population with symptomatic knee arthritis is likely to increase due to the combination of aging and obesity. osteoarthritis of Knee has more significance then important not only for its high prevalence rate compared with other types of OA primary because of its high prevalence but also for its increasing incidence and diagnosis in younger age group. The incidence of knee $\mathrm{OA}$ increases by age and further increase with longer lifetime and higher average weight of the population. ${ }^{2}$ Pain and other associated disabilities of OA have a profound effect on quality of life affecting activity of daily living and affecting both physical and psychological wellbeing. Knee OA is not a localized disease of cartilage alone but is considered as a chronic disease of the whole joint that can result from multiple pathophysiological mechanisms. It is painful and disabling disease that affects patient's world over. ${ }^{7}$

Genetic association studies have located 21 independent susceptibility loci for osteoarthritis. Primary focus of these studies have been focused on hip, knee and hand osteoarthritis, as well as post total joint arthroplasty 
patients. ${ }^{26}$ The role of MATN3 in cartilage homeostasis has been amply demonstrated by researchers who found that functional knockout of MATN3 in mice can lead to premature hypertrophy of articular chondrocytes which could be instrumental in development of osteoarthritis in adult mice. ${ }^{27}$ Belluoccio et al found that the matrix MATN3 molecule was present in every cartilage type. Their experimental cell culture demonstrated that MATN-3 could be a representative and harbinger of state of differentiation of cells obtained from the articular cartilage cells. ${ }^{28}$

Historical evidence from the published English literature fished out by us in favor of the role of MATN-3 in OA are summarized in Table 1 and, in a simple and straightway, it cannot be overemphasized that MATN-3 is an important gene in the skeletal development and its mutation make population vulnerable to develop degenerative Osteoarthritis.

There are several limitations in our systematic review. Firstly, the number of studies in literature for the topic has been less hence reducing sample size. In addition, the Chinese study also included osteoarthritis other than knees. This might weaken the strength of our findings. ${ }^{21}$ Secondly, we did not undertake a subgroup analysis of different study groups (Case and Control of all three studies.). Furthermore, not all the studies included large geographical population thus limiting genetic analysis in a small geographic area of the countries, which also reduces the power of our research. All 3 studies incidentally involve northeast area of the country (china, Egypt and India). ${ }^{20-23}$

To conclude, two among three studies has amply proven association of OA Knee and matrilin gene 3. ${ }^{20,21}$ The thirds Indian studies could not found that association but the third study was smaller in sample size and study duration The other explanation to this different conclusion of Indian study could be the difference in ethnicity too. ${ }^{23} \mathrm{On}$ that account of geographical location, all three studies have uncanny similarities of belonging to north east area of respective countries. To finally accept or refute this association between matrilin-3 gene and osteoarthritis in Indian population, larger sample based multicentric study could be the final answer and till then proverbial jury is still out. As of now, first study from the country have concluded that no association could be established. Identifying these correlations could actually pave the way for future studies in genetics in osteoarthritis and usher new era in arthritis research. Identifying genetic loci and subsequent cure for osteoarthritis could be a farfetched dream today but continuous research and relentless

\section{Table 1: Published literature on matrilin Gene-}

Klatt et al., 2009b (29)

The role of MATN-3 as a matrix degradation regulator in human cartilage is crucial and potent MATN-3dependent induction of the pro-inflammatory cytokines TNFa, IL-1b, IL-6, and IL-8, which are up-regulated in $\mathrm{OA}$. These pro-inflammatory cytokines boost the process of inflammation and induce different matrixdegrading enzymes, are therefore vital regulators of cartilage degradation. Apart from these attributes, MATN-3 induces iNOS and COX-2 gene; both are involved in the pathogenesis of OA, in cartilage. At last, MATN-3 induces the expression of MMP1, MMP3, and MMP13 in PHCs, which implies that MATN-3 acts as an intermediary and regulate ECM degradation.

Vincourt et al., 2008 (28) and Klatt et al., 2009b (29) In vitro characterization of MATN-3identified antianabolic and pro-catabolic functions, suggesting that it may actively participate in OA by an unknown mechanism.

Vincourt et al., 2012 (30)

Revealed higher levels of MATN-3 in both the serum and synovial fluid of OA patients.

Jayasuriya et al., 2012 (31) MATN-3 plays not only a structural role in cartilage $\mathrm{ECM}$, but also a regulatory role in cartilage homeostasis due to its capacity to induce IL-1Ra, to up regulate gene expression of the major cartilage matrix components, and to down regulate the expression of OA-associated matrix-degrading proteinases in chondrocytes.

Minafra et al., 2014 (32) polymorphisms in the foremost OA susceptibility genes including, GDF5 rs143383 \& DVWA rs11718863 genes and $\mathrm{KL}$ grading was hypothesized. The DVWA rs11718863 gene had a predictive role in OA progression, as associated with a more severe Radiographic grade. 
innovation will certainly go a long way in achieving that dream. In 1970s when Insall and Ranawat first introduced low friction knee prototype design, it opened the flood gate and sophisticated implant, improved technology and graduated surgical skills gradually developed in last 50 years. The Journey was never smooth and by their own admission, their Interest in knee arthroplasty began with the introduction of the MacIntosh hemi arthroplasty at the hospital for specialty surgery by Dr. Lee Ramsey Straub in 1968. ${ }^{29}$ They soon realized that the quality of arthroplasty, although better than any other intervention during those times, still was a compromise and complete pain relief and excellent functional outcome was not obtained.$^{30}$ Journey from that less than impressive start had come a long way and modern day implant design \&armamentarium are offering a survivorship of 22 years as per various registry data. ${ }^{31,32}$ Likewise we conclude that Genetic association studies with more collaboration among various research groups could find a breakthrough sooner or later to find a cure at genetic level for this multifactorial disorder and thus improve quality of life for many individuals. In the end we argue that these clinical genetic studies and their possible implication in cure of OA are the need of hour and shall be extensively funded. Knee salvage and keeping a natural knee alive is superior alternate any day than replacing it with best possible artificial metal or polyethylene components.

\section{ACKNOWLEDGEMENT}

Mogli Sharma, Gonu, Milind Sharma and Meenal Sharma for typing and Proof editing the manuscript.

\section{BIBLIOGRAPHY}

1. Felson DT. Epidemiology of hip and knee osteoarthritis. Epidemiol Rev 1988; 10:1-28.

https://doi.org/10.1093/oxfordjournals.epirev.a036019

2. Lawrence RC, Felson DT, Helmick CG, Arnold LM, Choi H, Deyo RA, et al. Estimates of the prevalence of arthritis and other rheumatic conditions in the United States. Part II. Arthritis Rheum 2008;58(1):26-35.

https://doi.org/10.1002/art.23176

3. Wallace IJ, Worthington S, Felson DT, Jurmain RD, Wren KT, Maijanen $\mathrm{H}$, et al. Knee osteoarthritis has doubled in prevalence since the mid-20th century. Proc Natl Acad Sci U S A 2017; 114(35):9332-9336.

https://doi.org/10.1073/pnas.1703856114

4. Altman RD. The syndrome of osteoarthritis. J Rheumatol 1997; 24:766-767.

https://doi.org/10.1016/S0160-7383(97)82467-X

5. Kishor $S$ and Garg BS. Socio medical problems of aged population in rural area of Wardha district. Indian $\mathrm{J}$ of public health 1997 ; 41:46-48.

6. Zahid A. Khan, Singh C and Khan T. A study of the leading cause of illness and physical disability in urban aged population. Indian J prev Soc Med 2000; 32:121-124.
7. Hunter DJ and Felson DT. Osteoarthritis. BMJ 2006; 332:639-642. https://doi.org/10.1136/bmj.332.7542.639

8. Reddi $\mathrm{AH}$. Role of morphogenic protein in skeletal tissue engineering and regeneration. Nat Biotechnol 1998; 16:247-252. https://doi.org/10.1038/nbt0398-247

9. Litwic A, Edwards MH, Dennison EM and Cooper C. Epidemiology and burden of osteoarthritis. Br Med Bull 2013; 105:185-199.

https://doi.org/10.1093/bmb/lds038

10. Spector TD, Cicuttini F, Baker J, Loughlin J and Hart D. Genetic influences on osteoarthritis in women: a twin study. BMJ 1996;312(7036):940-943.

https://doi.org/10.1136/bmj.312.7036.940

11. Palotie A, Väisänen $P$, Ott J, Ryhanen L, Elima K, Vikkula M, et al. Predisposition to familial osteoarthrosis linked to type II collagen gene. Lancet 1989;1(8644):924-927.

https://doi.org/10.1016/S0140-6736(89)92507-5

12. Kerkhof HJ, Lories RJ, Meulenbelt I, Jonsdottir I, Valdes AM, Arp $P$, et al. A genome-wide association study identifies an osteoarthritis susceptibility locus on chromosome 7q22. Arthritis Rheum 2010;62 (2):499-510.

https://doi.org/10.1002/art.27184

13. Dolan AL, Hart DJ, Doyle DV, Grahame R and Spector TD. The relationship of joint hypermobility, bone mineral density, and osteoarthritis in the general population: the Chingford Study. J Rheumatol 2003;30(4):799-803.

14. Chen HC, Shah SH, Li YJ, Stabler TV, Jordan JM and Kraus VB. Inverse association of general joint hypermobility with hand and knee osteoarthritis and serum cartilage oligomeric matrix protein levels. Arthritis Rheum 2008;58(12):3854-3864. https://doi.org/10.1002/art.24319

15. Evangelou E, Kerkhof HJ, Styrkarsdottir U, Ntzani EE, Bos SD, Esko $\mathrm{T}$, et al. A meta-analysis of genome-wide association studies identifies novel variants associated with osteoarthritis of the hip. Ann Rheum Dis. 2014;73(12):2130-2136.

https://doi.org/10.1136/annrheumdis-2012-203114

16. Aigner T and Dudhia J. Genomics of osteoarthritis. Curr Opin Rheumatol 2003;15(5):634-640.

https://doi.org/10.1097/00002281-200309000-00019

17. Klatt AR, Becker AK, Neacsu CD, Paulsson M and Wagener R. The matrilins: modulators of extracellular matrix assembly. Int $\mathrm{J}$ Biochem Cell Biol 2011;43(3):320-330.

https://doi.org/10.1016/j.biocel.2010.12.010

18. Chapman KL, Mortier GR, Chapman K, Loughlin J, Grant ME and Briggs MD. Mutations in the region encoding the von Willebrand factor A domain of matrilin- 3 are associated with multiple epiphyseal dysplasia. Nat Genet 2001; 28:393-396. https://doi.org/10.1038/ng573

19. Pullig $O$, Tagariello A, Schweizer A, Swoboda B, Schaller P and Winterpacht A. MATN3 (matrilin-3) sequence variation (pT303M) is a risk factor for osteoarthritis of the CMC1 joint of the hand, but not for knee osteoarthritis. Ann Rheum Dis 2007; 66: 279-280. https://doi.org/10.1136/ard.2006.058263

20. Trivedi V, Shah R, Qidwai S, Mishra AN, Raza T, Kushwaha SS, et al. Association between MATN-3 Gene Polymorphism and Primary Knee Osteoarthritis in Indian Population: A CommunityBased Case-Control Study. Fortune Journal of Rheumatology 2 (2020): 001-012. https://doi.org/10.26502/fjr.26880012

21. Gu J, Rong J, Guan F, Jiang L, Tao S, Guag G, et al. MATN3 gene polymorphism is associated with osteoarthritis in Chinese Han population: a community-based case-control study. Scientific 
World Journal 2012; 2012:656084.

https://doi.org/10.1100/2012/656084

22. Altman R, Asch E, Bloch D, Bole G, Borenistin D, Brandt $K$ et al. Development of criteria for the classification and reporting of osteoarthritis. Classification of osteoarthritis of the knee. Diagnostic and Therapeutic Criteria Committee of the American Rheumatism Association. Arthritis Rheum 1986; 29:1039-1049. https://doi.org/10.1002/art.1780290816

23. Diab SM, Kamal HM, Mansour Al, Fawzy RM and Azab BS. Clinical significance of matrilin-3 gene polymorphism in Egyptian patients with primary knee osteoarthritis. Eur J Rheumatol 2017; 4 (3):200-204

https://doi.org/10.5152/eurjrheum.2016.16107

24. Kellgren JH and Lawrence JS. Radiological assessment of osteoarthrosis. Ann Rheum Dis 1957; 16:494-502.

https://doi.org/10.1136/ard.16.4.494

25. Lequesne M, Mery C, Samson M and Gerard P. Indexes of severity for osteoarthritis of the hip and knee. Scand J Rheumatol Suppl 1987;65:85- 89.

https://doi.org/10.3109/03009748709102182

26. Warner SC and Valdes AM. Genetic association studies in osteoarthritis: is it fairytale?. Curr Opin Rheumatol 2017;29(1):103-109.

https://doi.org/10.1097/BOR.0000000000000352

27. Van der Weyden L, Wei L, Luo J, Yang X, Birk E, Adams D, et al.
Functional knockout of the matrilin-3 gene causes premature chondrocyte maturation to hypertrophy and increases bone mineral density and Osteoarthritis. Am J Pathol 2006;169:51. https://doi.org/10.2353/ajpath.2006.050981

28. Belluoccio D, Schenker T, Baici A and Trueb B. Characterization of human matrilin-3 (MATN3) Genomics 1998;53: 391-394. https://doi.org/10.1006/geno.1998.5519

29. Maclntosh DL and Hunter GA. The use of the hemiarthroplasty prosthesis for advanced osteoarthritis and rheumatoid arthritis of the knee. J Bone Joint Surg Br 1972;54(2):244-255. https://doi.org/10.1302/0301-620X.54B2.244

30. Insall JN, Ranawat CS, Scott WN and Walker P. Total condylar replacement-Preliminary report. Clin Orthop 1976; 120: 149-154. https://doi.org/10.1097/00003086-197610000-00023

31. Milligan DJ, O'Brien S, Doran E, Gallagher NE and Beverland DE. Twenty-year survivorship of a cemented mobile bearing Total Knee Arthroplasty. Knee 2019;26(4):933-940. https://doi.org/10.1016/j.knee.2019.06.004

32. Callaghan JJ, Martin CT, Gao Y, Pugeli AJ, Liu SS, Goetz DD, et al. What can be learned from minimum 20-year follow up studies of knee arthroplasty? Clin Orthop Relat Res 2015;473(1):94-100.

https://doi.org/10.1007/s11999-014-3744-1

\section{Authors Contribution:}

AKS, DS, AS and RCM - Concept and design; AKS, UR, PS, SMK- Manuscript typing, editing and final approval; RS, DS, AS, PS and UR - Literature search, Interpretation, analysis, supervision; RS, DS, DG and PS - Data collection; All authors-final approval of manuscript

\section{Work attributed to:}

Department of Orthopedics, SMS Medical College, Jaipur, India

Orcid ID:

Dr. Arun Kumar Sharma- (i) https://orcid.org/0000-0002-1688-8003

Dr. Rajbeer Singh- (1) https://orcid.org/0000-0001-5621-0566

Dr. Devendra Singh- https://orcid.org/0000-0002-6058-5448

Dr. Anurag Shukla- https://orcid.org/0000-0001-6329-2408

Dr. Ramesh C Meena- (i) https://orcid.org/0000-0002-8705-6722

Dr. Divyanshu Goyal- https://orcid.org/0000-0001-8893-1878

Priyanka Sharma- (i) https://orcid.org/0000-0001-9797-2743

Dr. Uday Raman- (iD https://orcid.org/0000-0002-7450-6261

Source of Support: Nil, Conflict of Interest: None declared. 